\title{
Aerodynamic Design Optimization of Range Extension Kit of a Subsonic Flying Body
}

\author{
A. M. Elsherbiny ${ }^{*}$, A. M. Bayoumy ${ }^{\dagger}$, A. M. Elshabka ${ }^{\ddagger}$ and M. M. Abdelrahman ${ }^{\S}$
}

\begin{abstract}
This paper aims to convert the aerodynamic shape of a conventional aerial subsonic flying body into a glide one by providing a range extension kit and fins. It describes the selection of configuration and airfoils depending on the tactical requirements and flight regimes. The wing and fins sizing is obtained using three different methods subjected to geometric constraints. The first method is an iterative optimization method using linear aerodynamic data. The second method is a genetic algorithm multi-objective function aims to maximize stability, controllability and lift-drag ratio within certain weights using linear aerodynamic data. The third method is a genetic algorithm optimization function integrated with MISSILE DATCOM aims to maximize lift-drag ratio. Then perform a direct uncontrolled six degree of freedom simulation for the three optimized designs and the conventional flying body. Comparing the results of ranges for these bodies reveals that the third method has the best range over the other designs including the conventional flying body.
\end{abstract}

Keywords: Aerodynamic Design, Subsonic Flying body, Range Extension Kit, Optimization, Genetic algorithm, MISSILE DATCOM, 6DoF simulation.

\section{Nomenclature}

$$
\begin{array}{rrrr}
C_{L}, C_{D}, C_{m} & \begin{array}{r}
\text { Lift, drag, and pitching } \\
\text { moment coefficients }
\end{array} & C_{Y}, C_{l}, C_{n} & \begin{array}{r}
\text { Lateral force, rolling, and } \\
\text { yawing moment coefficients }
\end{array} \\
C_{L o}, C_{D o}, C_{m o} & \begin{array}{r}
\text { Lift, drag, and pitching } \\
\text { moment coefficients at } \\
\text { zero values of } \alpha, \mathrm{q}, \delta, \\
\text { and } \dot{\alpha}
\end{array} & C_{Y o}, C_{l o}, C_{n o} & \begin{array}{r}
\text { Lateral force, rolling, and } \\
\text { yawing moment coefficients at } \\
\text { zero values of } \beta, \mathrm{p}, \mathrm{r} \text {, and } \delta
\end{array} \\
& \begin{array}{rlr}
\text { Derivatives of lift } \\
C_{L \alpha}, C_{L q},
\end{array} & C_{Y \beta}, C_{Y p}, & \begin{array}{c}
\text { Derivatives of lateral force } \\
C_{L \delta_{p}}, C_{L \dot{\alpha}}
\end{array} \\
\begin{array}{r}
\text { coefficient w.r.t. } \alpha, \mathrm{q}, \\
\delta_{p}, \text { and } \dot{\alpha}
\end{array} & C_{Y r}, C_{Y \delta_{r}} & \text { coefficient w.r.t. } \beta, \mathrm{p}, \mathrm{r} \text {, and } \delta_{r}
\end{array}
$$

\footnotetext{
*M.Sc. Student, MTC, Cairo, Egypt, abdallahelsherbiny2@gmail.com

$\dagger$ Assistant Prof, MSA University, Giza, Egypt, ambayoumy@msa.eun.eg

† Assistant Prof, MTC, Cairo, Egypt, ahmedelsebaee@mtc.edu.eg

$\S$ Prof, Cairo University, Cairo, Egypt, dr_madbouli@staff.cu.edu.eg
} 


\begin{tabular}{|c|c|c|c|}
\hline $\begin{array}{l}C_{m \alpha}, C_{m q} \\
C_{m \delta_{p}}, C_{m \dot{\alpha}}\end{array}$ & $\begin{array}{r}\text { Derivatives of moment } \\
\text { coefficient w.r.t. } \alpha, \mathrm{q}, \\
\delta_{p} \text {, and } \dot{\alpha}\end{array}$ & $\begin{array}{l}C_{l \beta}, C_{l p} \\
C_{l r}, C_{l \delta_{r}}\end{array}$ & $\begin{array}{l}\text { Derivatives of rolling moment } \\
\text { coefficient w.r.t. } \beta, \mathrm{p}, \mathrm{r} \text {, and } \delta_{r}\end{array}$ \\
\hline $\begin{array}{l}C_{n \beta}, C_{n p} \\
C_{n r}, C_{n \delta_{r}}\end{array}$ & $\begin{array}{r}\text { Derivatives of yawing } \\
\text { moment coefficient } \\
\text { w.r.t. } \beta, \mathrm{p}, \mathrm{r} \text {, and } \delta_{r}\end{array}$ & $c_{w}, c_{r f}, c_{t f}$ & Wing, root, and tip chords [m] \\
\hline$D C M$ & $\begin{array}{r}\text { Directional cosines } \\
\text { matrix }\end{array}$ & $\vec{F}_{B}$ & $\begin{array}{r}\text { Resultant external force vector } \\
\text { applied on the flying body in } \\
\text { body axes [N] }\end{array}$ \\
\hline$\vec{g}_{o}$ & $\begin{array}{r}\text { Gravity acceleration } \\
\text { vector }\left[\mathrm{m} / \mathrm{s}^{2}\right]\end{array}$ & $h_{n}, h_{m}$ & Neutral and maneuver points \\
\hline $\boldsymbol{I}_{B}$ & $\begin{array}{r}\text { Inertia matrix in body } \\
\text { axes }\left[\mathrm{N} . \mathrm{m}^{2}\right]\end{array}$ & $m$ & Flying body mass $[\mathrm{Kg}]$ \\
\hline$p, q, r$ & $\begin{array}{r}\text { Scalar components of } \\
\text { angular velocity in body } \\
\text { axis }[\mathrm{rad} / \mathrm{sec}]\end{array}$ & $u, v, w$ & $\begin{array}{r}\text { Scalar components of linear } \\
\text { velocity in body axis }[\mathrm{m} / \mathrm{s}]\end{array}$ \\
\hline$\vec{V}_{B}$ & $\begin{array}{r}\text { velocity vector in body } \\
\text { axis }[\mathrm{m} / \mathrm{s}]\end{array}$ & $V_{H}$ & Horizontal-tail volume ratio \\
\hline$V_{t}$ & Total velocity $[\mathrm{m} / \mathrm{s}]$ & $x, y, z$ & $\begin{array}{r}\text { Components of vehicle } \\
\text { trajectory [m] }\end{array}$ \\
\hline$\alpha, \beta$ & Wind angles [deg] & $\rho_{H_{-} \text {air }}$ & Air density at $(\mathrm{H})$ altitude \\
\hline$\delta_{r}, \delta_{p}, \delta_{y}$ & $\begin{array}{r}\text { Roll, pitch, and yaw fin } \\
\text { deflection angles [deg] }\end{array}$ & $\mu$ & Relative mass parameter \\
\hline$\phi, \theta, \psi$ & $\begin{array}{r}\text { Roll, pitch, and yaw } \\
\text { angles (Euler angles) } \\
\text { [deg] }\end{array}$ & $\vec{\omega}_{B}$ & $\begin{array}{r}\text { Angular velocity vector in } \\
\text { body axis }[\mathrm{rad} / \mathrm{s}]\end{array}$ \\
\hline
\end{tabular}

\section{Introduction}

In the last 40 years, there are a global need for long range air-to-surface munitions which are associated with low cost-effectiveness, and standoff. So, a glide flying bodies are developed which is a category between conventional aerial bomb and tactical air-to-ground missile featured with a high benefit-cost ratio. These munitions can be loaded on bomb carriers, fighters and other combat aircrafts which are capable of carrying aerial bombs. In 1980, Randall [14] introduced an aerodynamic design of an extended range bomb to provide a low altitude, $15 \mathrm{~km}$ stand-off, a $2.5 \mathrm{~km}$ turn radius, and return-to-target (RTT) delivery capability from aircraft at release speeds of 330-800 KCAS. The bomb is a canard configuration, this canard is used for attitude control and lift. The optimization of canard design is performed using wind tunnel tests. In 1994, Wakayama and Kroo [11] introduced subsonic wing design using multidisciplinary optimization. The objective function was to minimize the drag subject to maximum lift and minimum structural weight and the design parameters was the wing planform. In 1995, Anderson [12] introduced the potential of genetic algorithms for subsonic wing design to determine high efficiency wing planform geometries. The objective function was to maximize aerodynamic efficiency (lift-drag ratio). In 1996, Anderson and Gebert [10] introduced the using of Pareto genetic algorithms to determine high efficiency wing geometries, and demonstrates the capability of pareto genetic algorithms to determine highly efficient and robust wing designs given a variety 
of design goals and constraints. The design goals are maximizing lift-drag ratio and minimizing structure weight. The design parameters are wing planform, height of wing along span, and wing twist. In 1998, Austin [9] introduced an investigation of range extension with a genetic algorithm. The optimization is aimed to increase the range depending on the inputs to a six degree of freedom simulation. The parameters to be optimized were the inputs to this motion generator and the simulator's output (terminal range) was the fitness measure. The parameters of interest were initial launch altitude, initial launch speed, wing angle-of-attack, and engine ignition time. In 1999, Vicini and Queagliarella [8] introduced airfoil and wing design through hybrid optimization strategies. This hybrid optimization algorithm has been obtained by adding a gradient based technique among the set of operators of a multi-objective genetic algorithm. In 2007, Lei Tang et al. [7] introduced extension of projectile range using oblique-wing concept. A body-conformal oblique wing/tails with smart-structure control has been proposed to achieve an extended range with full optimal scheduling of L/D from subsonic to supersonic speeds using an intensive thinlayer Reynolds-averaged Navier-Stokes computations. In 2008, Takahashi [6] described a comprehensive study of wing sizing and configuration for subsonic cruise air-vehicles by maximizing (L/D) at the design speed. In 2015, Andrews and Perez [4] introduced a parametric study of box-wing aerodynamics for minimum drag under stability and maneuverability constraints. They aim to optimize the wing planform by maximizing the aerodynamic efficiency while enforcing three constraints: the ability to maintain inherent static stability at cruise, the ability to perform a maneuver without stalling, and the ability to generate sufficient lift to support the aircraft at cruise conditions. In 2016, Viti et al. [1] introduced a preliminary aircraft design procedure in a multidisciplinary context for new aircraft configurations by optimizing top level variables that directly impact both aerodynamics and structure. A CFDCSM model with a DAKOTA gradient based optimization method is used to perform the optimization process. In 2016, Russell M. Cummings et al. [2] introduced an aerodynamics and conceptual design studies on an unmanned combat aerial vehicle configuration by predicting both static and dynamic stability characteristics of air vehicles using computational fluid dynamics methods aiming to reduce the number of ground tests required to verify vehicle concepts.

In this paper, a comprehensive study is introduced for extension kit and fins design optimization. The design optimization is done through two main steps. First step is the configuration and airfoils selections subject to the tactical requirements. Second step is the range extension kit and fins sizing optimization using three different methods subjected to geometric constraints. The first method is an iterative method aims to reach a certain stability characteristics using theoretical aerodynamic data. The second method is a multi-objective genetic algorithm, aims to maximize the aerodynamic efficiency, stability and maneuverability. In this method a pareto front is introduced showing the effect of changing wing and fins parameters on the required objective functions. Third method is an optimization using integration between multiple softwares. This method introduce a developed Matlab code that integrates MISSILE DATCOM and Matlab genetic algorithm to obtain maximum aerodynamic efficiency subject to stability constraints. A six degree of freedom (6DoF) simulations for the conventional flying body and the three optimized designs are performed and comparisons between the results are introduced. Using the output of these methods as an initial guess to a high level optimization will decrease the cost and time in wing and fins designs.

\section{Configuration and Airfoils Selections}

To start the design, the technical requirements should be specified by knowing the tactical requirements. Tactical requirements are Stand-off attack flying body (range $\geq 60 \mathrm{Km}$ ), high subsonic release velocity, and attacking enemy fixed target such as command center, runways, naval ports, etc. The technical requirements can be stated as a high lift-drag ratio and a cruising subsonic Mach number $(0.6 \leq M \leq 0.8)$ to meet the tactical requirements. 
Aerodynamic design mainly has two objectives, the first is to achieve small zero-lift drag and high lift-drag ratio to make sure the flying body's range is far enough, the other is to achieve control and stability characteristic which meet the requirements to enable the flying body to fly reliable and stable.

\subsection{Configuration Selection}

Flying body configurations can be divided into plane symmetrical configuration and axis symmetrical configuration as shown in Figure 1. The plane-symmetrical configuration (symmetry about vertical plane) has a largest lift plane. The flying body generates a large normal force, a large load factor and a high lift-drag ratio in the normal direction in this plane. But it has a rather weak maneuver capability in the lateral direction. So, the plane symmetrical configuration is suitable for attacking fixed targets. The axis-symmetrical configuration (symmetry about longitudinal axis) usually has the fin and the wing arranged crossly along the flying body. In this case, the normal force has the isotropy which is suitable for attacking the high maneuver target. Consequently, the plane-symmetrical configuration is the best configuration to achieve the specified tactical requirements.
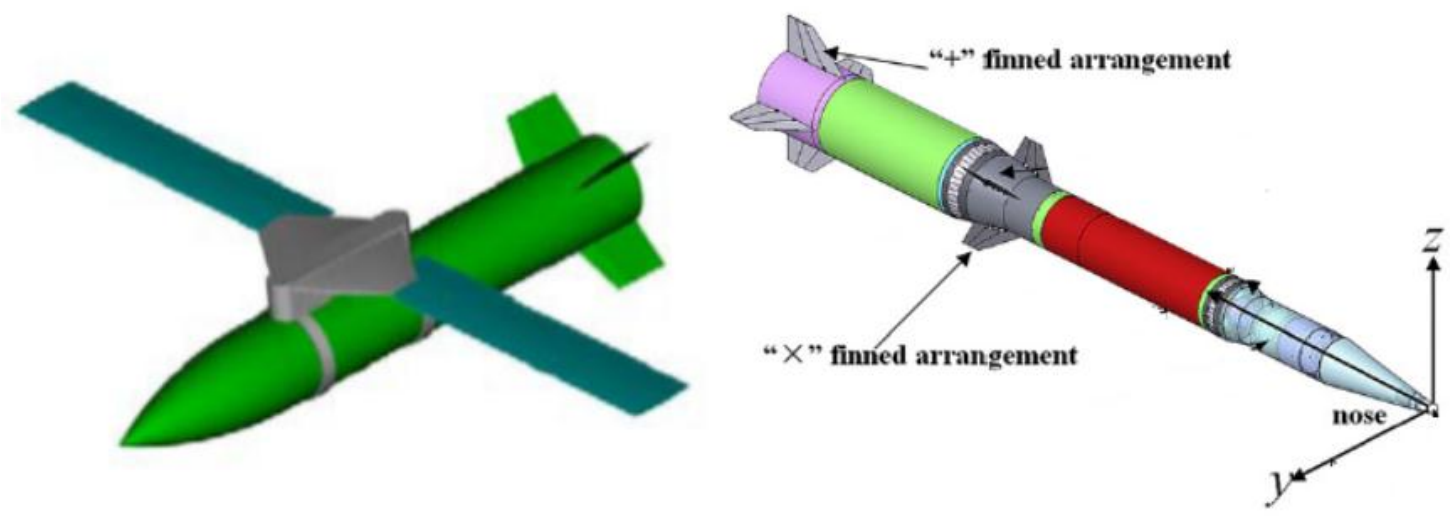

Figure 1 Plane-symmetrical configuration (left) and axis symmetrical configuration (right)

\subsection{Airfoil Selection}

There are many classifications of airfoils according to speed range employed such as low speed, subsonic, transonic and supersonic airfoils and the corresponding airfoil. According to the technical requirements, main flight scope is flight altitude is $0-12 \mathrm{Km}$, major flight altitude is $6000 \mathrm{~m}$, and major flight Mach number is 0.7. So, a high speed subsonic airfoil would be selected. The requirements of minimizing the zero-lift drag coefficient and increasing the critical Mach number can be achieved using laminar airfoil profile. These laminar airfoils are the rather perfect subsonic airfoils. Because the airfoil drag is mainly friction when flying with low angle of attack, studies indicates that the drag of laminar airfoil can be reduced more than half compared with the drag of common turbulent airfoil. Therefore, it is significant that the method of increasing scope of airfoil laminar surface flow is used to reduce the airfoil drag and increase the lift-drag ratio. The best known laminar airfoil includes airfoil in NACA6 series. Choosing inside NACA6 series should be considered from several aspects which are lift coefficient, lift line slope, drag characteristics, and moment characteristics. Depending on these factors, NACA 64A212 airfoil is chosen for the wing, and NACA 65006 symmetric airfoil is chosen for the fin.

\section{Range Extension Kit Sizing}

The longitudinal stability and maneuverability dynamics can be used to obtain the wing kit and fins dimensions to achieve a desired trimming angle. The optimization is subjected to technical requirement, geometric, and stability constraints. Technical requirement constraint is 
maximum range which can be transformed to maximum lift-drag ratio in gliding. Geometric constraints are wing span, wing chord, fin span, and fin trailing edge location. Wing semi-span must be less than the distance between wing leading edge and fin leading edge positions with a clearance $1 \mathrm{~cm}\left(L_{g a b}\right)$ to ensure a clear unfolding of wing. Wing chord in folded position must not exceed the component of fin span in lateral direction. Fin span limitation results from the aircraft pylon dimensions and position w.r.t. airplane and other suspension systems, so the maximum fin span can be chosen as 3 times of flying body diameter. Fin trailing edge location must not exceed the flying body length $\left(\boldsymbol{L}_{\boldsymbol{b t o t}}\right)$, so the aerodynamic center position of the fin root chord must not exceed the flying body length minus 0.75 fin chord. Stability constraints are positive pitch stiffness (negative pitch moment curve slope), and aerodynamic center location must be behind the flying body center of gravity $\left(X_{c g}\right)$ which is located at $1105^{ \pm 15} \mathrm{~mm}$ from flying body nose.

\subsection{Range Extension Kit Optimization Using Iterative Process}

Theoretical stability equations $(3.1-3.18)$ are used in wing and fins sizing to achieve a desired value of trimming angle [13]. The optimization is subjected to technical requirement, geometric, and stability constraints. This method has many assumed parameters, these parameters are wing leading edge position, sweepback angles for both wing and fins $\left(\chi_{w}, \chi_{f}\right)$, and fins span $\left(b_{f}\right)$. The advantage of this method is obtaining the wing and fins dimensions and locations in an easy and simple manner. The procedures of this method are as follows:

1. From airfoil's polar curve, maximum $\left(\mathrm{C}_{\mathrm{L}} / \mathrm{C}_{\mathrm{D}}\right)$ is obtained at optimum glide angle.

2. From the lift curve, optimum angle of attack $\alpha_{\text {opt }}$ can be obtained using the value of $\mathrm{C}_{\mathrm{L}}$ optimum.

3. Assume an initial value for the wing chord $\left(c_{w}\right)$, and leading edge position for fins $\left(x_{f l}\right)$.

4. Calculate wing span $\left(b_{w}\right)$ from geometric restriction using equation (3.1).

5. Calculate wing aspect ratio $(A)$.

6. Calculate the wing lift curve slope with compressibility effect using equation (3.2).

7. From the trimming condition calculate the wing area $\left(S_{w}\right)$ using equation (3.3).

8. Calculate the new values of wing span and chord from the calculated area and aspect ratio.

9. Calculate the aerodynamic center at the mid of semi span using equation (3.4).

10. Obtain the value of fin tip chord $\left(c_{t f}\right)$ that satisfy the desired trimming angle by getting all coefficients in equation (3.5) using equations $(3.6-3.15)$ as function of fin tip chord.

11. Calculate the new values of fin leading edge position using equation (3.16).

12. Repeat procedures from step 3 to 11 till the process converges at error $<10^{-5}$ using equation (3.19).

13. During each iteration, pitch deflection angle per $\mathrm{g}\left[\Delta \delta_{p} / n\right]$ is calculated using equation (3.17) where $n$ is the load factor.

$$
\begin{aligned}
& b_{\text {semi }}=x_{\boldsymbol{f l}}-\boldsymbol{x}_{w \boldsymbol{l}}-L_{g a b} \\
& a_{w}=a_{o} /\left(\sqrt{1-M_{\infty}^{2}}+\frac{a_{o}}{\pi A}\right) \\
& S_{w}=m g /\left(0.5 \rho_{H_{-} a i r} V^{2} C_{L w}\right) \\
& X_{A C m}=X_{W L}+0.25 c_{w}+0.25 b_{w} \tan \left(\chi_{w}\right) \\
& \delta_{t r i m}=\frac{-\left(C_{m o} C_{L \alpha}+C_{m \alpha} C_{L t r i m}\right)}{C_{L \alpha} C_{m \delta}-C_{m \alpha} C_{L \delta}} \\
& C_{L \alpha}=a_{w}\left(1+\frac{a_{f} S_{f}}{a_{w} S_{w}}\right)
\end{aligned}
$$


$C_{m \alpha}=C_{L \alpha}\left(h-h_{n}\right)$

$$
h=X_{c g} / c_{w}, \quad h_{n}=X_{A C m} / c_{w}
$$

$C_{L \delta}=a_{f} S_{f} / S_{w}$

$C_{m \delta}=-a_{f} V_{H}$

$V_{H}=\frac{l_{t}}{c_{w}} \frac{S_{f}}{S_{w}}$

$l_{t}=\left(l_{b t o t}-0.75 c_{r f}\right)-X_{c g}$

$c_{r f}=c_{t f}+h_{f} \tan \chi_{f}$

$S_{f_{-} \text {one }}=h_{f} c_{t f}+0.5 h_{f}\left(h_{f} \tan \chi_{f}\right)$

$S_{f}=4 S_{f_{-} \text {one }} \cos (45)$

$x_{F L}=\left(L_{b t o t}-c_{r f}\right)$

$\Delta \delta_{p} / n=\frac{-\left(C_{L \alpha} C_{L t r i m}\right)}{C_{L \alpha} C_{m \delta}-C_{m \alpha} C_{L \delta}}\left(h-h_{m}\right)$

$h_{m}=h_{n}-\frac{C_{m q}}{2 \mu}, \quad C_{m q}=-2 a_{f} l_{t} /\left(c_{w} V_{H}\right), \mu=\frac{2 m}{\rho S_{w} c_{w}}$

$E=\left[x_{F L}(i+1)-x_{F L}(i)\right] / x_{F L}(i)$

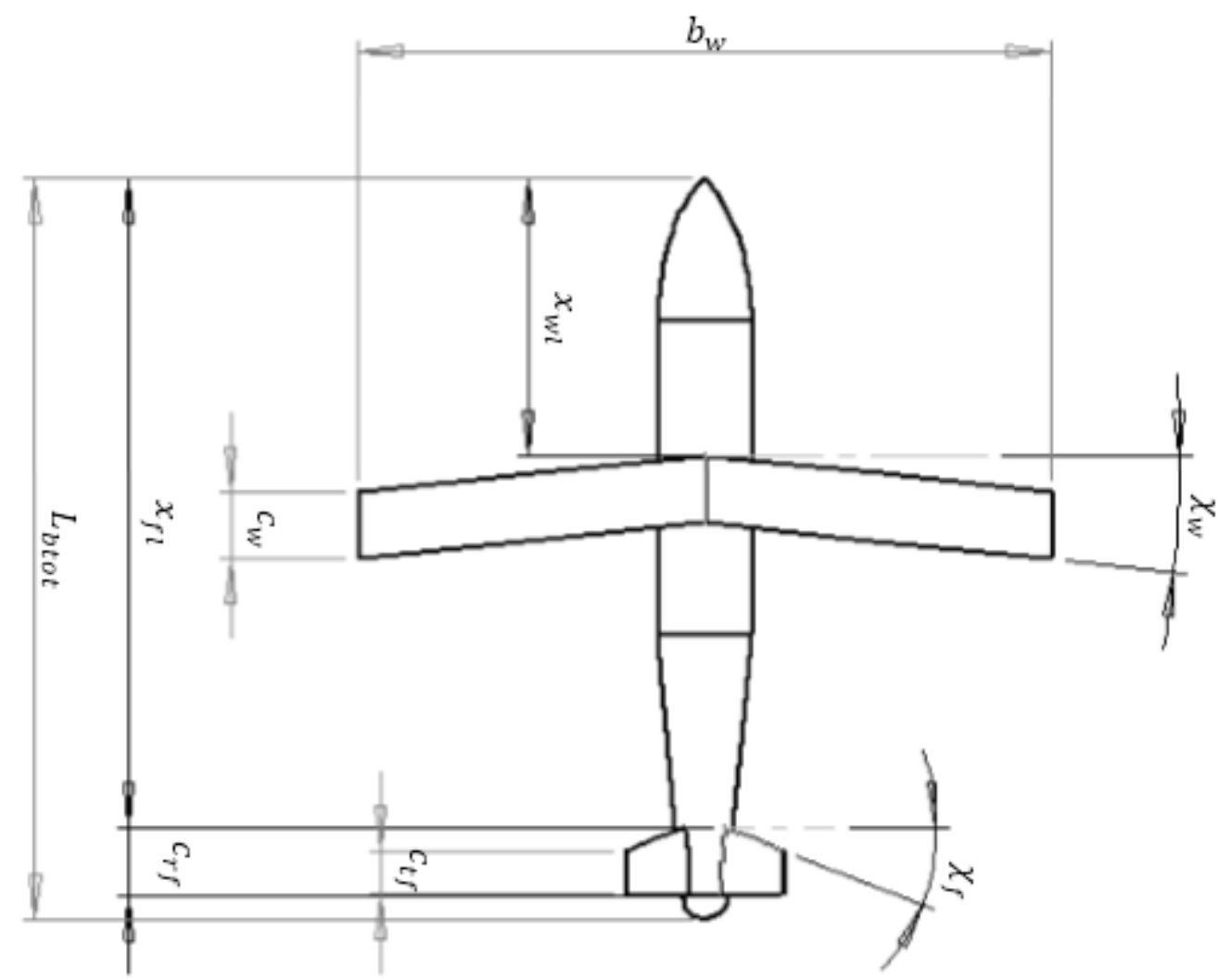

Figure 2. Shows the parameters of wing and fins 

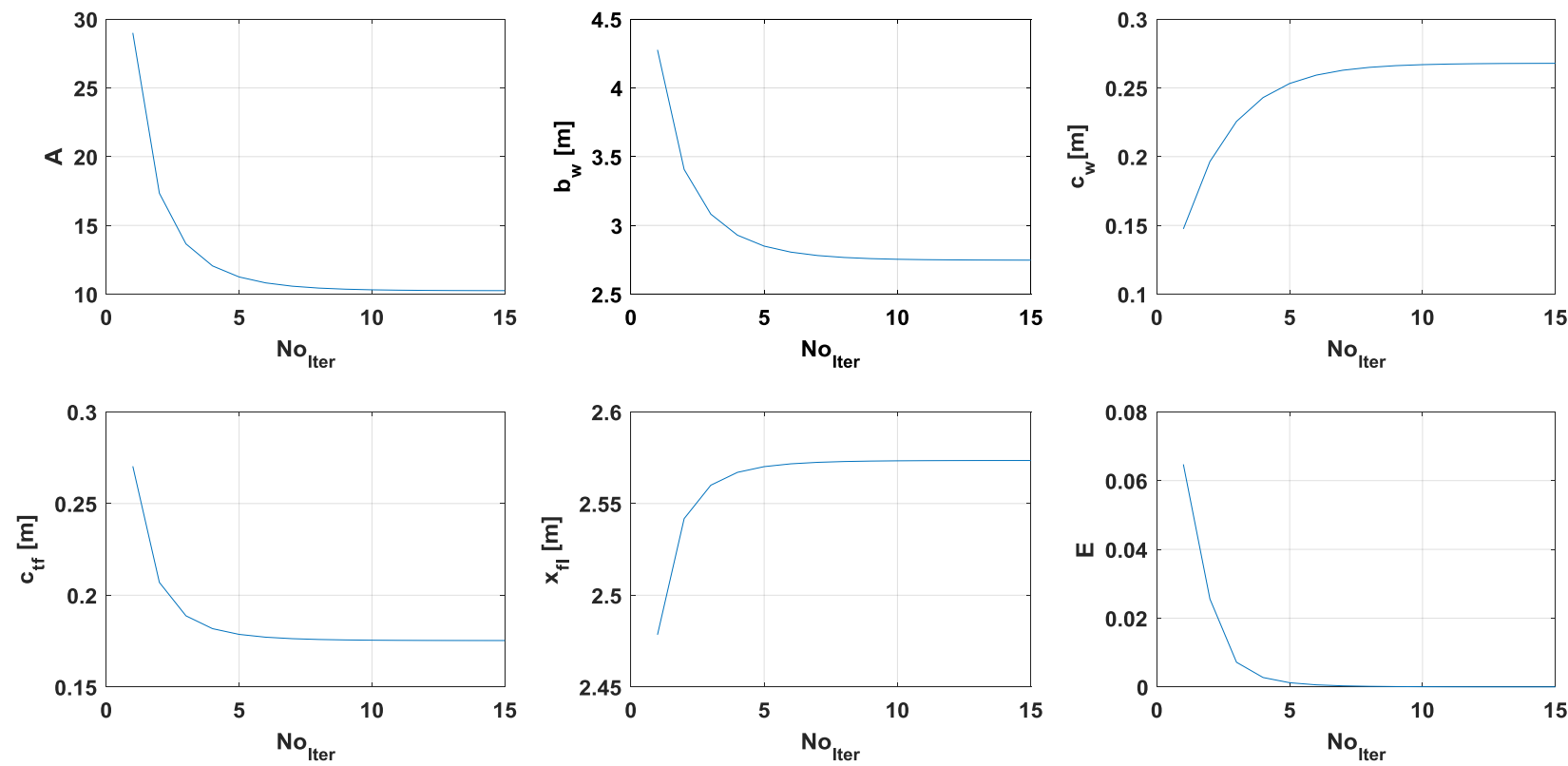

Figure 3. Values of converge results

A Matlab code is developed to perform this iterative process. As shown in Figure 3, the initial wing aspect ratio reduced from 28 to 10 , also during the study if the initial aspect ratio changed greater or less than 10 , the final value is the same. During iterations, fins leading edge position moves backward, wing area increases and fin area decreases to decrease the static stability which leads to achieve a small trimming angle. Initial wing span calculated from aspect ratio not satisfy the geometric constrains, so as decreasing wing span, wing chord is increased to achieve the desired wing area. Choosing a small trimming angle leads to increase the maneuverability. This also can be shown as the absolute value of pitch deflection angle per g decreases. In this method, choosing a high or low trimming angle leads to a design with high stability or maneuverability respectively. The results of the parameters are shown in Table 1.

Table 1. 1st method parameters

\begin{tabular}{|l|c|}
\hline \multicolumn{1}{|c|}{ Parameter } & Value \\
\hline Wing leading edge position [m] & 1.1 \\
\hline Fin leading edge position[m] & 2.5735 \\
\hline Wing chord [m] & 0.26794 \\
\hline Fin tip chord [m] & 0.17528 \\
\hline Fin sweep [Deg.] & 16 \\
\hline Fin span [m] & 0.89 \\
\hline Wing sweep [Deg.] & 6 \\
\hline Wing span [m] & 2.747 \\
\hline
\end{tabular}

\subsection{Range Extension Kit Optimization Using Multi-Objective Function Genetic Algorithm with Linear Aerodynamic Data}

This method introduces a multi objective optimization using linear aerodynamic data to increase the range, stability, and maneuverability. Range increases as lift-drag ratio increases, maneuverability increases as pitch deflection angle per $\mathrm{g}\left(\delta_{p} / n\right)$ decreases, and stability increased as pitch stiffness $\left(-\boldsymbol{C}_{\boldsymbol{m} \boldsymbol{\alpha}}\right)$ increases. 
The optimization problem can be defined as: the objective functions is to minimize drag-lift ratio $\left(C_{D} / C_{L}\right)$, pitch deflection angle per $\mathrm{g}$, and pitching moment curve slope $\left(-\boldsymbol{C}_{\boldsymbol{m} \boldsymbol{\alpha}}\right)$ using the same theoretical equations used in the first method, subjected to the geometric and stability constraints $\boldsymbol{G}(\boldsymbol{X})$. The problem can be mathematically defined as:

$$
\begin{gathered}
\text { Minimize } f_{1}(X)=C_{D} / C_{L} \\
\text { Minimize } f_{2}(X)=C_{m} \alpha \\
\text { Minimize } f_{3}(X)=\delta_{p} / n \\
\boldsymbol{G}(\boldsymbol{X}) \leq \mathbf{0}, \quad \boldsymbol{X} \geq \mathbf{0}
\end{gathered}
$$

Subject to

The optimization parameters $\boldsymbol{X}$ are the wing leading edge position, fin leading edge position, wing chord, fin tip chord, and wing span, while fin span, wing and fins sweepback angles are assumed.

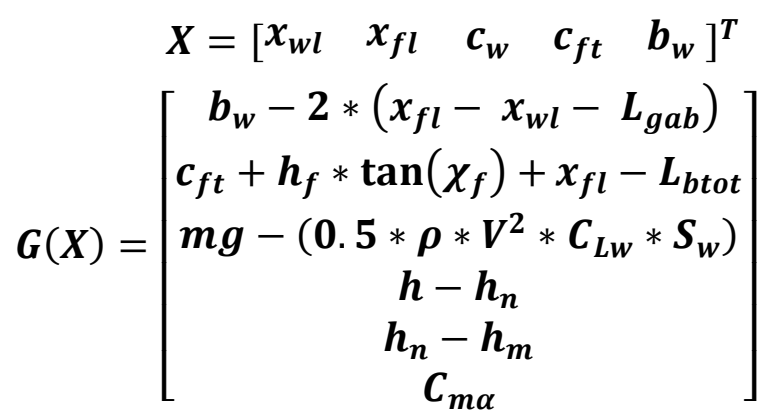

The multi-objective function can be solved using genetic algorithm. A MATLAB code is developed to perform the optimization with initial population size equal to 200 , lower bounds $\mathbf{L}_{\mathbf{B}}=[1.0,2.3,0.2,0.15,1.5]^{\mathrm{T}}$ and upper bounds $\mathbf{U}_{\mathbf{B}}=[1.2,2.7,0.35,0.2,3.5]^{\mathrm{T}}$. the flow chart of the $2^{\text {nd }}$ method is illustrated in Figure 4 and the results of the objectives and optimization parameters are shown in Table 2 .

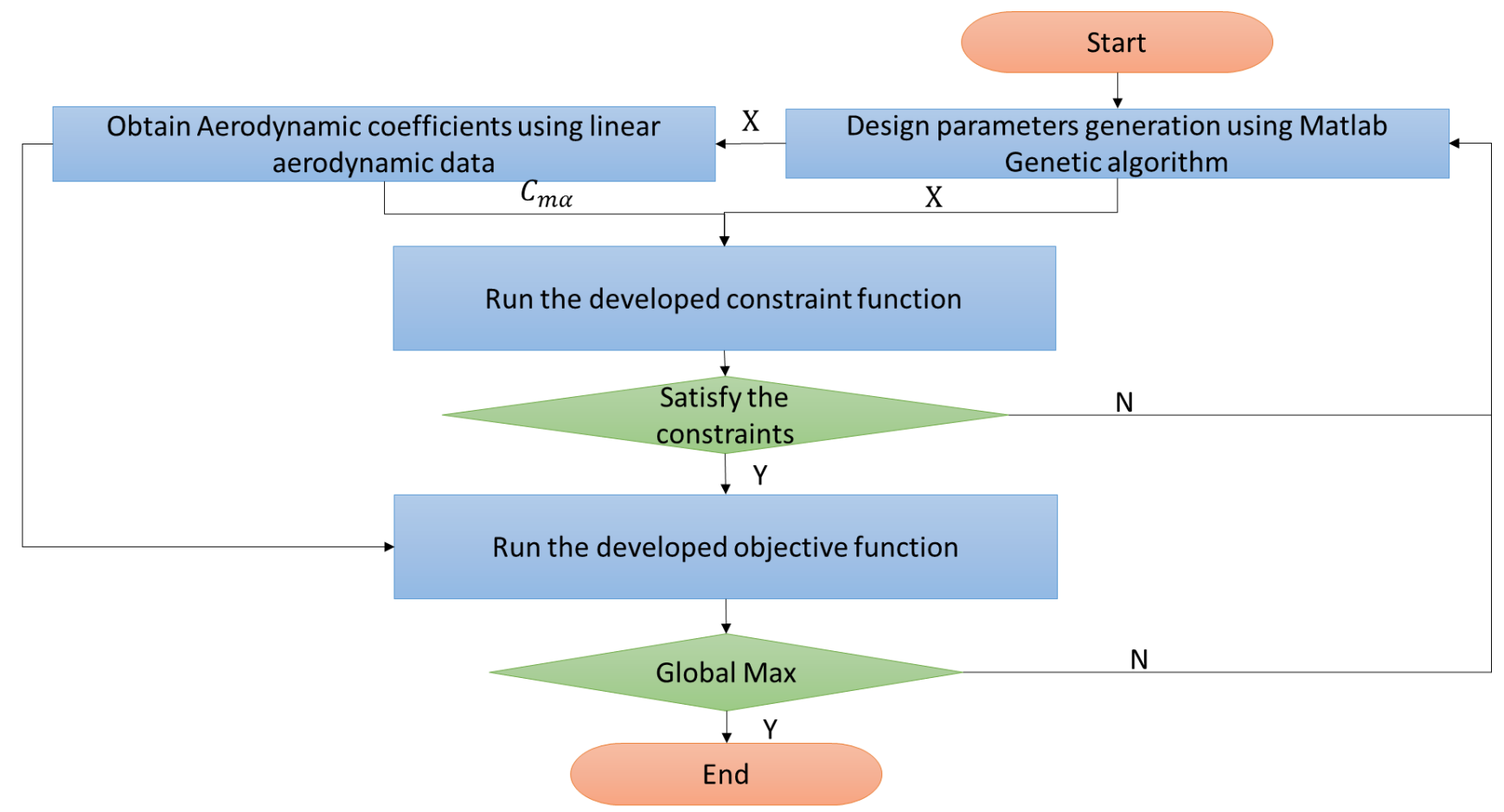

Figure 4. Second optimization method flow chart 
Table 2. Objective and optimization parameters using $2^{\text {nd }}$ method

\begin{tabular}{|c|c|c|c|c|c|c|c|c|}
\hline \multirow{2}{*}{$\begin{array}{c}\text { Point } \\
\text { No. }\end{array}$} & \multicolumn{3}{|c|}{ Objectives } & \multicolumn{5}{c|}{ Optimization Parameters } \\
\cline { 2 - 9 } & $\boldsymbol{C}_{\boldsymbol{D}} / \boldsymbol{C}_{\boldsymbol{L}}$ & $\boldsymbol{C}_{\boldsymbol{m} \boldsymbol{\alpha}}$ & $\boldsymbol{\delta}_{\boldsymbol{p}} / \boldsymbol{n}$ & $\boldsymbol{x}_{\boldsymbol{w} \boldsymbol{l}}$ & $\boldsymbol{x}_{\boldsymbol{f} \boldsymbol{l}}$ & $\boldsymbol{c}_{\boldsymbol{w}}$ & $\boldsymbol{c}_{\boldsymbol{f} \boldsymbol{t}}$ & $\boldsymbol{b}_{\boldsymbol{w}}$ \\
\hline $\mathbf{1}$ & 0.0263 & -0.0386 & -0.0115 & 1.1000 & 2.5778 & 0.2732 & 0.1523 & 2.8045 \\
\hline $\mathbf{2}$ & 0.0253 & -0.0259 & -0.0065 & 1.0719 & 2.5807 & 0.2553 & 0.1652 & 2.8353 \\
\hline $\mathbf{3}$ & 0.0256 & -0.0421 & -0.0109 & 1.0999 & 2.5821 & 0.2585 & 0.1633 & 2.8107 \\
\hline $\mathbf{4}$ & 0.0253 & -0.0351 & -0.0089 & 1.0869 & 2.5807 & 0.2553 & 0.1628 & 2.8340 \\
\hline $\mathbf{5}$ & 0.0253 & -0.0318 & -0.0080 & 1.0815 & 2.5807 & 0.2553 & 0.1649 & 2.8353 \\
\hline $\mathbf{6}$ & 0.0257 & -0.0410 & -0.0114 & 1.0999 & 2.5786 & 0.2614 & 0.1537 & 2.8074 \\
\hline $\mathbf{7}$ & 0.0254 & -0.0403 & -0.0101 & 1.0958 & 2.5809 & 0.2567 & 0.1674 & 2.8205 \\
\hline $\mathbf{8}$ & 0.0253 & -0.0341 & -0.0087 & 1.0853 & 2.5809 & 0.2553 & 0.1620 & 2.8340 \\
\hline $\mathbf{9}$ & 0.0253 & -0.0342 & -0.0086 & 1.0854 & 2.5810 & 0.2553 & 0.1637 & 2.8344 \\
\hline $\mathbf{1 0}$ & 0.0253 & -0.0259 & -0.0065 & 1.0719 & 2.5807 & 0.2553 & 0.1652 & 2.8353 \\
\hline $\mathbf{1 1}$ & 0.0261 & -0.0396 & -0.0115 & 1.0999 & 2.5785 & 0.2679 & 0.1524 & 2.8057 \\
\hline $\mathbf{1 2}$ & 0.0256 & -0.0421 & -0.0109 & 1.0999 & 2.5821 & 0.2585 & 0.1633 & 2.8107 \\
\hline $\mathbf{1 3}$ & 0.0253 & -0.0353 & -0.0090 & 1.0873 & 2.5810 & 0.2554 & 0.1628 & 2.8340 \\
\hline $\mathbf{1 4}$ & 0.0253 & -0.0366 & -0.0093 & 1.0893 & 2.5813 & 0.2555 & 0.1628 & 2.8340 \\
\hline $\mathbf{1 5}$ & 0.0254 & -0.0385 & -0.0099 & 1.0930 & 2.5807 & 0.2563 & 0.1614 & 2.8252 \\
\hline $\mathbf{1 6}$ & 0.0253 & -0.0290 & -0.0073 & 1.0769 & 2.5807 & 0.2553 & 0.1651 & 2.8353 \\
\hline $\mathbf{1 7}$ & 0.0253 & -0.0317 & -0.0081 & 1.0814 & 2.5809 & 0.2553 & 0.1625 & 2.8344 \\
\hline
\end{tabular}
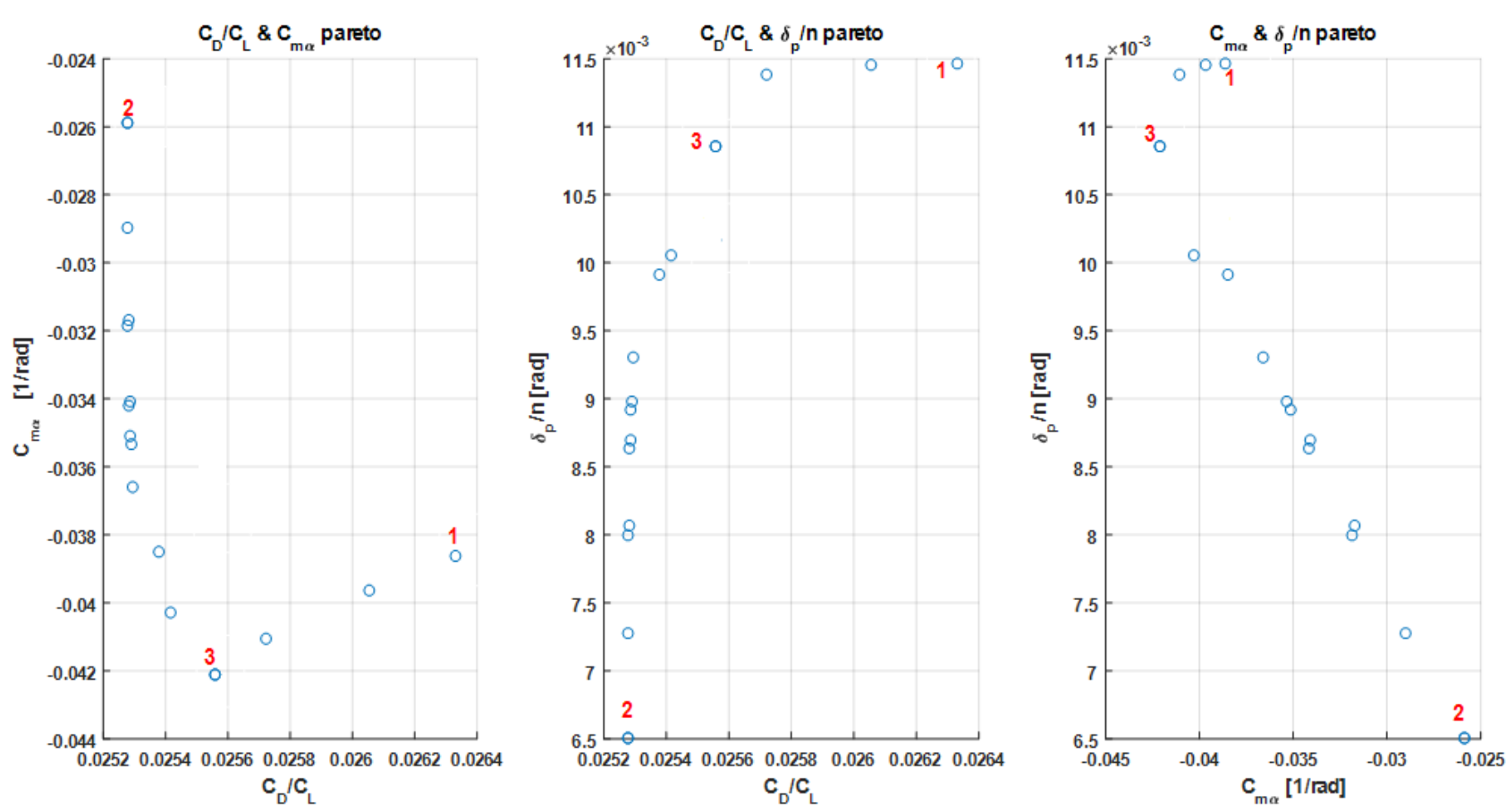

Figure 5 Pareto diagram for multiple weights of the stability, maneuverability and lift-drag ratio 
By tracing the scatter points in Figure 5, pitching stiffness increases as pitch deflection angle per $\mathrm{g}$ decreases. Lift drag ratio increases as pitch deflection angle per $\mathrm{g}$ increases and pitching stiffness decreases. Point number 1 has a moderate stability characteristics (maximum pitch stiffness), but it has the min values of lift-drag ratio and pitch deflection angle per $g$ so it is the worst point. Point number 2 has the optimum values of both lift-drag ratio and pitch deflection angle per $\mathrm{g}$, but has a bad stability characteristics (minimum pitch stiffness). Point number (3) has good values for the three objectives where it has the highest value of pitching stiffness among all points but it has a relatively bad maneuverability and a good lift-drag ratio. Whereas the flying body is designed to attack fixed targets, so the stability will have a higher priority than the maneuverability. The other points has a higher values for lift-drag ratio but has either bad stability or bad maneuverability. As a result, the point number (3) in table 2 will be selected as optimized design point of the second method. The $2^{\text {nd }}$ method parameters are shown in Table 3.

Table 3. $2^{\text {nd }}$ method parameters

\begin{tabular}{|l|c|}
\hline \multicolumn{1}{|c|}{ Parameter } & Value \\
\hline Wing leading edge position [m] & 1.0999 \\
\hline Fin leading edge position[m] & 2.5821 \\
\hline Wing chord [m] & 0.2585 \\
\hline Fin tip chord [m] & 0.1633 \\
\hline Fin sweep [Deg.] & 16 \\
\hline Fin span [m] & 0.89 \\
\hline Wing sweep [Deg.] & 6 \\
\hline Wing span [m] & 2.8106 \\
\hline
\end{tabular}

\subsection{Range Extension Kit Optimization Using Genetic Algorithm of Nonlinear Aerodynamic Data}

This method has no assumed values, all wing and fins dimensions, locations and angles are used as optimization parameters. A MATLAB code is developed to perform the integration between the optimization toolbox on MATLAB and the MISSILE DATCOM. First the optimization parameters are generated. Then the code generates a MISSILE DATCOM input file, run its executable file, and imports the MISSILE DATCOM output file. Then calculates lift-drag ratio which is the objective function needed to be maximized and pitching moment curve slope which indicates the longitudinal stability. The process will be repeated till it reach the global maximum of lift to drag ratio as long as the design parameters and pitching moment curve slope are satisfy the geometric and stability constraints as shown in Figure 6. 


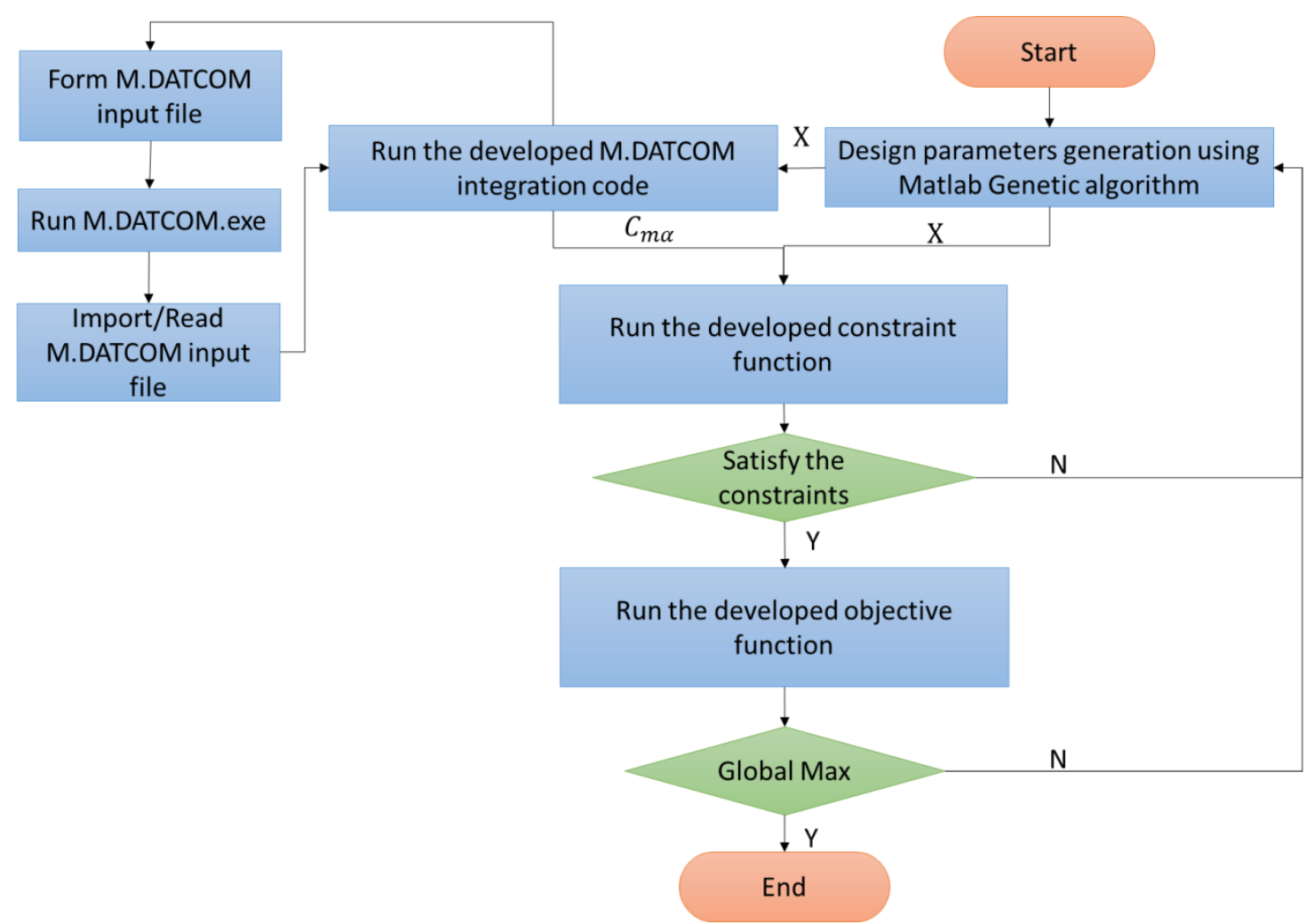

Figure 6. Third optimization method flow chart

The optimization problem can be defined as follows:

$$
\text { Minimize } f(X)=C_{D} / C_{L}
$$

Subject to

$$
\boldsymbol{G}(\boldsymbol{X}) \leq \mathbf{0}, \quad \boldsymbol{X} \geq \mathbf{0}
$$

$$
X=\left[\begin{array}{llllllll}
x_{w l} & x_{f l} & c_{w} & c_{f t} & b_{w} & b_{f} & \chi_{w} & \chi_{f}
\end{array}\right]^{T}
$$

The constraints $\boldsymbol{G}(\boldsymbol{X})$ can be defined as follows:

$$
G(X)=\left[\begin{array}{c}
b_{w}-2 *\left(x_{f l}-x_{w l}-L_{g a b}\right) \\
c_{f t}+h_{f} * \tan \left(\chi_{f}\right)+x_{f l}-L_{b t o t} \\
m g-\left(0.5 * \rho * V^{2} * C_{L w} * S_{w}\right) \\
C_{m \alpha}
\end{array}\right]
$$

The initial population equal 60, upper and lower bound are $\mathbf{L}_{\mathbf{B}}=\left[\begin{array}{lll}1.01 & 2.30 .200 .120 .610 .0\end{array}\right.$

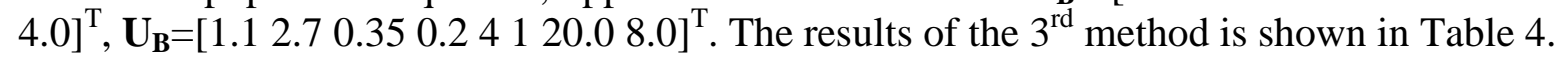

Table 4. $3^{\text {nd }}$ method parameters

\begin{tabular}{|l|c|}
\hline \multicolumn{1}{|c|}{ Parameter } & $\mathbf{3}^{\text {rd }}$ method \\
\hline Wing leading edge position [m] & 1.0652 \\
\hline Fin leading edge position[m] & 2.5945 \\
\hline Wing chord [m] & 0.2985 \\
\hline Fin tip chord [m] & 0.1514 \\
\hline Fin sweep [Deg.] & 16.75 \\
\hline Fin span [m] & 0.97 \\
\hline Wing sweep [Deg.] & 4.7297 \\
\hline Wing span [m] & 2.624 \\
\hline
\end{tabular}




\subsection{Aerodynamic Characteristics and Design Parameters Comparison of the Three Methods}

The aerodynamic characteristics and design parameters comparisons are shown in Figure 7 and Table 5 respectively.

Table 5. Parameters comparison between the three design methods. ()* means assumed values

\begin{tabular}{|l|c|c|c|}
\hline \multicolumn{1}{|c|}{ Parameter } & $\mathbf{1}^{\text {st }}$ method & $\mathbf{2}^{\text {nd }}$ method & $\mathbf{3}^{\text {rd }}$ method \\
\hline Wing leading edge position [m] & $1.1^{*}$ & 1.0999 & 1.0652 \\
\hline Fin leading edge position[m] & 2.5735 & 2.5821 & 2.5945 \\
\hline Wing chord [m] & 0.26794 & 0.2585 & 0.2985 \\
\hline Fin tip chord [m] & 0.17528 & 0.1633 & 0.1514 \\
\hline Fin sweep [Deg.] & $16^{*}$ & $16^{*}$ & 16.75 \\
\hline Fin span [m] & $0.89^{*}$ & $0.89^{*}$ & 0.97 \\
\hline Wing sweep [Deg.] & $6^{*}$ & $6^{*}$ & 4.7297 \\
\hline Wing span [m] & 2.747 & 2.8106 & 2.624 \\
\hline
\end{tabular}
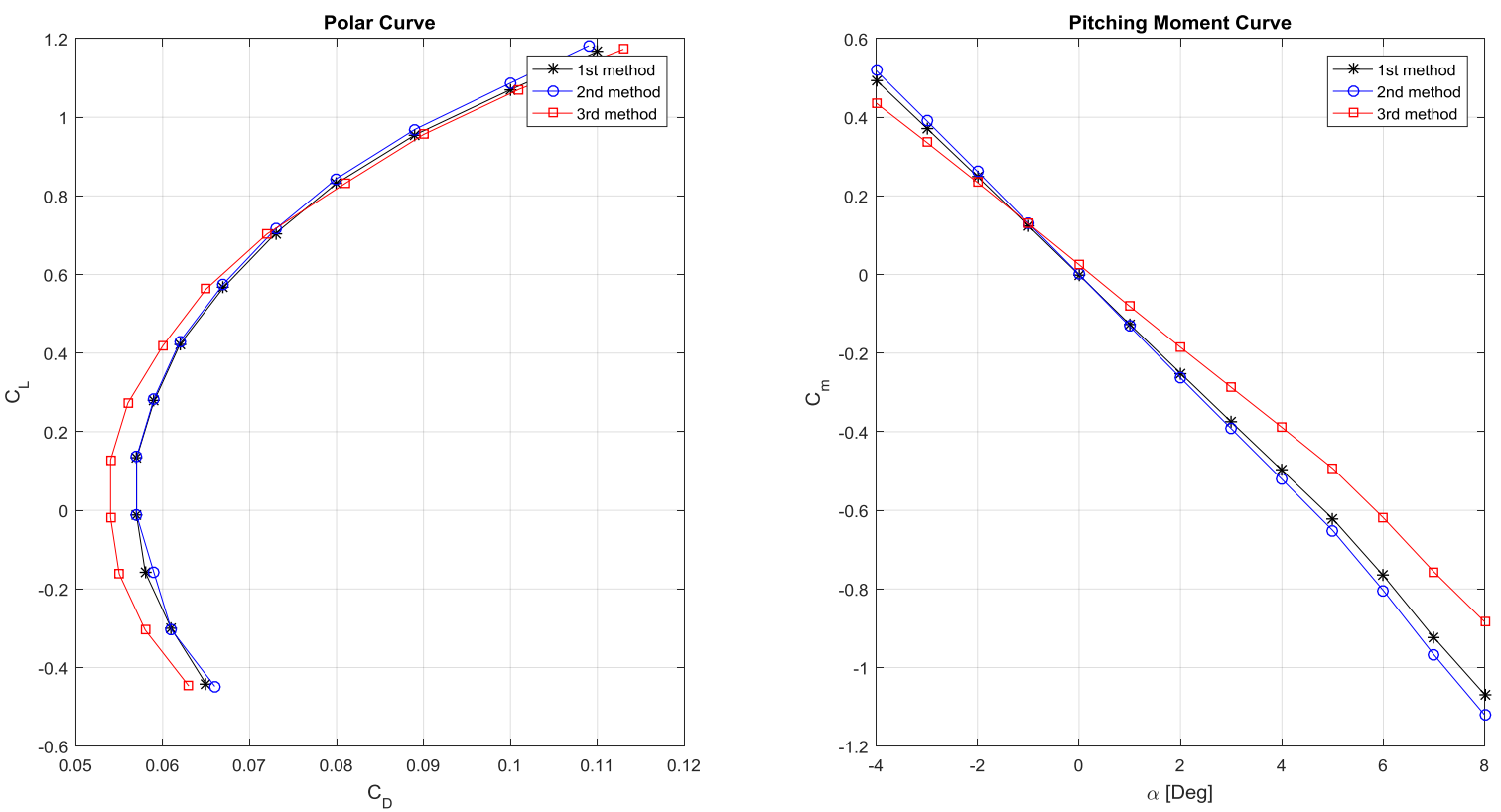

Figure 7. Aerodynamic characteristics comparison of the three design methods

By comparing the design parameters of the three methods from table 5 . The $1^{\text {st }}$ method has four assumed values, $2^{\text {nd }}$ method has three assumed values and $3^{\text {rd }}$ method doesn't have any assumed values. From polar curve shown in Figure 7, the lift-drag ratio of the third method is much more than the two other methods at the range of applied angles of attack, then the $2^{\text {nd }}$ method comes in the second place although it has a high lift-drag ratio but at very high angles of attack. From the pitching moment curve shown in Figure 7, all the three methods have a positive pitch stiffness and the second curve has the steepest slope and zero pitching moment coefficient equal zero $\left(C_{m o} \approx 0\right)$, so the $2^{\text {nd }}$ method has the most favorable stability characteristics. Since $\left(C_{m o} \approx 0\right)$ for the three cases, a control surface deflection must be applied to obtain trimming angle of attack that leads to the maximum aerodynamic efficiency. The elapsed time of the $3^{\text {rd }}$ optimization method is greater than the other methods, because of the increment of design parameters and the integration between the multiple software to obtain the nonlinear aerodynamic data. But it produces more accurate aerodynamic data and more design parameters. To have more evaluation, an uncontrolled six degree of freedom simulation has been performed. 


\section{Flying body Modeling and Simulation}

\subsection{Mathematical Modeling}

The first step to develop a six degree of freedom nonlinear flight simulation model for a flying body is to develop the mathematical model that describes the flying body dynamics and its surroundings. The mathematical model includes the flying body Dynamic model (equations of motion) which describes the flying body dynamics [3], the aerodynamic model which describes the aerodynamic forces and moments represented in the body frame, gravity model which describes the gravity force, mass-inertia model which describes the mass and inertia properties of the total configuration of the flying body, and atmosphere model which describes the change in atmosphere parameters along the flight.

\subsubsection{Dynamic model}

This dynamic model contains the nonlinear differential equations. These equations of motion are developed assuming that the flying body is a rigid body, Earth is flat and non-rotating, and $\mathrm{x}-\mathrm{z}$ plane is the flying body plane of symmetry.

These equations can be classified into four main vector equations (force, moment, attitude, and trajectory equations), force and moment equations are developed from Newton's second law and they are applied in the flying body axis, attitude equations are derived from Euler method, and since the flying body position updates occur in the Earth frame so the trajectory equation is used by transforming the flying body velocities to linear position rates in the Earth axis.

The standard six degrees of freedom nonlinear differential equations for a flying body, using Euler's angles are as follows:

Force equation:

Moment equation:

Attitude equation:

Trajectory equation:

$$
\begin{aligned}
& \overrightarrow{\dot{V}}_{B}=-\vec{\omega}_{B} \times \vec{V}_{B}+\boldsymbol{B} \vec{g}_{o}+\vec{F}_{B} / m \\
& \overrightarrow{\dot{\omega}}_{B}=\boldsymbol{I}_{\boldsymbol{B}}{ }^{-1}\left[-\left(\vec{\omega}_{B} \times \boldsymbol{I}_{B} \vec{\omega}_{B}\right)+\vec{M}_{B}\right] \\
& \vec{\Phi}_{B}=f(\Phi) \vec{\omega}_{B} \\
& \overrightarrow{\mathrm{r}}_{E}=\boldsymbol{B}^{T} \vec{V}_{B}
\end{aligned}
$$

These vector equations are in the form of a state space vector $\dot{\boldsymbol{X}}=f(\boldsymbol{X}, \boldsymbol{U})$, each vector equation include three unidirectional equations, so it represent twelve equations with twelve state vectors $X$ where $X=\left[\begin{array}{llllllllllll}V_{t} & \boldsymbol{\alpha} & \boldsymbol{\beta} & \boldsymbol{p} & \boldsymbol{q} & \boldsymbol{r} & \boldsymbol{\phi} & \boldsymbol{\theta} & \boldsymbol{\psi} & \boldsymbol{x} & \boldsymbol{y} & \boldsymbol{z}\end{array}\right]^{\boldsymbol{T}}$ and $\boldsymbol{U}$ is the control input vector.

In our case study, the forces are represented in the body frame due to aerodynamic forces $\vec{F}_{B}^{a e r o}$ and gravity forces $\vec{F}_{B}^{\text {grav }}$ (no thrust) and the moment represented also in body frame due to aerodynamic moments $\vec{M}_{B}^{a e r o}$ only.

\subsubsection{Aerodynamic Model}

The aerodynamic model introduces the total aerodynamic forces and moments, the forces and moments can be written as follows:

$\vec{F}_{w}^{\text {aero }}=\left[\begin{array}{lll}D & Y & L\end{array}\right]$

$\vec{M}_{B}^{a e r o}=\left[\begin{array}{lll}\underline{L} & M & N\end{array}\right]$

These aerodynamic forces and moments can be classified into longitudinal and lateral forces and moments [5]. The longitudinal forces and moments are affected by the angle of attack $\alpha$ and its derivative $\dot{\alpha}$, pitch deflection angle $\delta_{p}$ and pitch rate $q$. The lateral forces and 
moments are affected by the sideslip angle $\beta$, rolling deflection angle $\delta_{r}$, roll rate $p$, yaw deflection angle $\delta_{y}$, and yaw rate $r$.

The longitudinal loads are lift force $L$, drag force $D$, and pitching moment $M$ are given by:

$$
\begin{aligned}
& L=0.5 \rho V_{t}^{2} S C_{L}\left(\alpha, q, \delta_{p}, \dot{\alpha}\right) \\
& D=0.5 \rho V_{t}^{2} S C_{D}(\alpha, q, \dot{\alpha}) \\
& M=0.5 \rho V_{t}^{2} S c_{w} C_{M}\left(\alpha, q, \delta_{p}, \dot{\alpha}\right)
\end{aligned}
$$

Also, lateral loads are side force $Y$, roll moment $\underline{L}$, and yaw moment $N$ are given by:

$$
\begin{aligned}
& Y=0.5 \rho V_{t}^{2} S C_{Y}\left(\beta, p, r, \delta_{r}\right) \\
& \underline{L}=0.5 \rho V_{t}^{2} S b_{w} C_{l}\left(\beta, p, r, \delta_{r}\right) \\
& N=0.5 \rho V_{t}^{2} S b_{w} C_{n}\left(\beta, p, r, \delta_{r}\right)
\end{aligned}
$$

Equations (4.6) and (4.7) can be rewritten using linear approximation as:

$$
\begin{aligned}
& L=0.5 \rho V_{t}^{2} S\left[C_{L o}+C_{L \alpha} \alpha+C_{L \delta_{p}} \delta_{p}+C_{L q}\left(c / 2 V_{T}\right) q+C_{L \dot{\alpha}}\left(c / 2 V_{T}\right) \dot{\alpha}\right] \\
& D=0.5 \rho V_{t}^{2} S\left[C_{D o}+k C_{L}^{2}\right] \\
& M=0.5 \rho V_{t}^{2} S c_{w}\left[C_{m o}+C_{m \alpha} \alpha+C_{m \delta_{p}} \delta_{p}+C_{m q}\left(c / 2 V_{T}\right) q+C_{m \dot{\alpha}}\left(c / 2 V_{T}\right) \dot{\alpha}\right] \\
& Y=0.5 \rho V_{t}^{2} S\left[C_{Y o}+C_{Y \beta} \beta+C_{Y \delta_{r}} \delta_{r}+C_{Y \delta_{y}} \delta_{y}+C_{Y p}\left(b / 2 V_{T}\right) p+C_{Y r}\left(b / 2 V_{T}\right) r\right] \\
& \underline{L}=0.5 \rho V_{t}^{2} S b_{w}\left[C_{l o}+C_{l \beta} \beta+C_{l \delta_{r}} \delta_{r}++C_{Y \delta_{y}} \delta_{y}+C_{l p}\left(b / 2 V_{T}\right) p+C_{l r}\left(b / 2 V_{T}\right) r\right] \\
& N=0.5 \rho V_{t}^{2} S b_{w}\left[C_{n o}+C_{n \beta} \beta+C_{n \delta_{r}} \delta_{r}+C_{Y \delta_{y}} \delta_{y}+C_{n p}\left(b / 2 V_{T}\right) p+C_{n r}\left(b / 2 V_{T}\right) r\right]
\end{aligned}
$$

All the aerodynamic coefficient in equations (4.8) and (4.9) is calculated using MISSILE DATCOM through a developed Matlab code that reads the geometry data of the flying body from an excel sheet. This process is done for different Mach numbers, altitudes, roll deflection angles and pitch deflection angles to give a full representation of aerodynamic coefficients through the flight for both conventional and optimized flying bodies. The aerodynamic forces are transformed from wind frame to body frame using the direction cosine matrix:

$$
\vec{F}_{B}^{a e r o}=(D C M)_{w \rightarrow B} \vec{F}_{w}^{a e r o}
$$

\subsubsection{Gravity Model}

Gravity model introduces the gravity forces of the flying body in body frame $\vec{F}_{B}^{\text {grav }}$ by converting the gravity force from Earth frame $\vec{F}_{E}^{\text {grav }}$ to body frame where:

$$
\vec{F}_{B}^{\text {grav }}=m g\left[\begin{array}{cc}
-\sin \theta \\
\cos \theta & \sin \phi \\
\cos \theta & \cos \phi
\end{array}\right]
$$

\subsubsection{Mass-Inertia Model}

The mass and inertia of the flying body are $m=500[\mathrm{Kg}], I_{x x}=8.2, I_{y y}=105.1$, and $I_{z z}=108.4\left[\mathrm{Kg} \cdot \mathrm{m}^{2}\right]$.

\subsubsection{Atmosphere Model}

The maximum release altitude of the flying body is $11[\mathrm{Km}]$, so the flight will be in Troposphere layer where the temperature changes linearly with rate of $-6.5[\mathrm{~K} / \mathrm{Km}]$. 


\subsection{Flying body Simulation}

The simulation is performed by using a developed MATLAB code. It starts at time equal zero with the initial conditions. The initial conditions are: $M_{i}=0.7, H_{i}=5000[\mathrm{~m}], v_{i}=w_{i}=$ $0, x_{i}=y_{i}=0, \vec{\Phi}_{i}=0, \vec{\omega}_{i}=0$, and $u_{i}$ is calculated using $M_{i}, H_{i}$. The total forces and moments are calculated using the aerodynamic model, mass-inertia model, atmosphere model and gravity model (eqns. 4.5 to 4.11 ) at a fixed pitch deflection angles (uncontrolled motion). The state vector derivatives are calculated by using the dynamic model (eqns. 4.1 to 4.4). Then the state vector is obtained using Runge-Kutta $4^{\text {th }}$ order numerical integration method with time step 0.01 second till $\mathrm{H}=0$. Figure 8 shows the flow chart of the flying body simulation process. The results of the simulations are shown in figures 9-15.

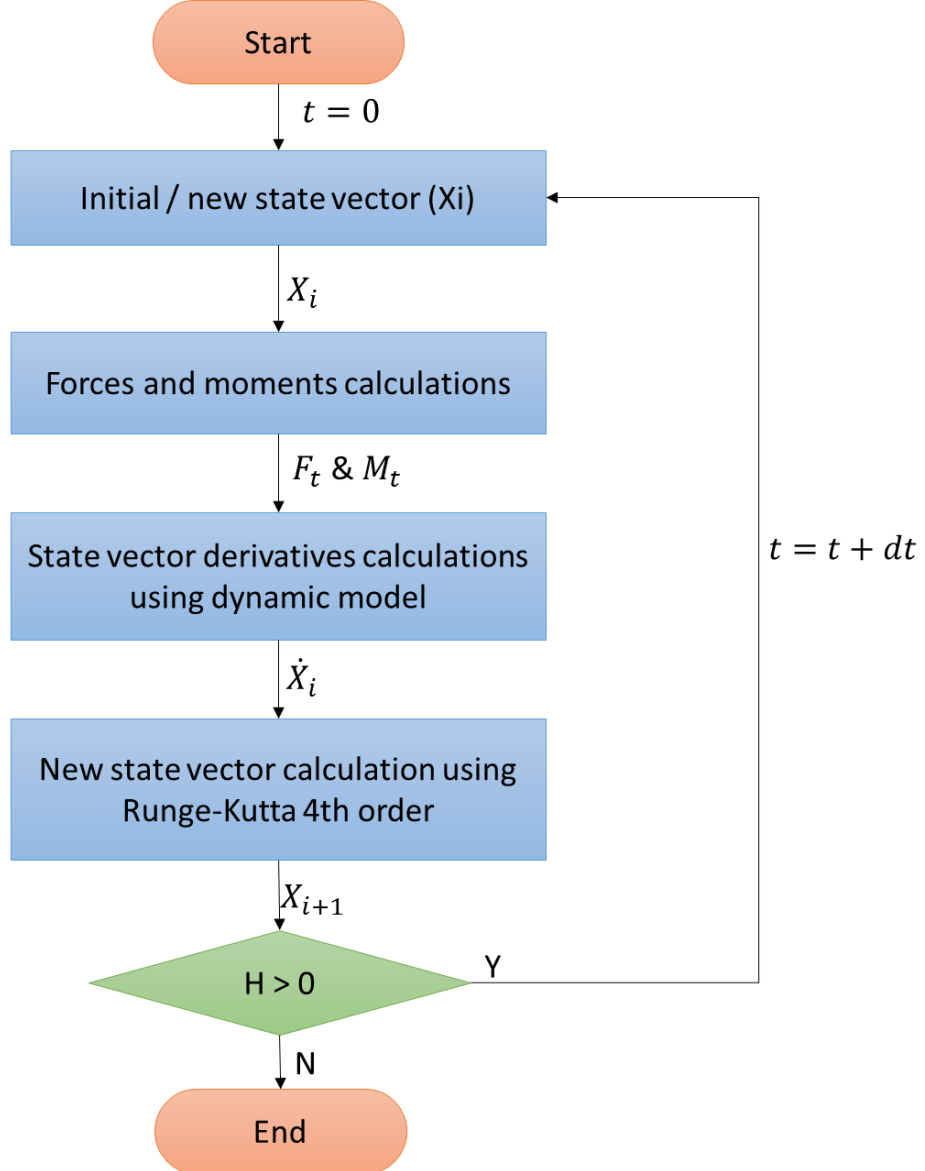

Figure 8. Flying body simulation process flow chart 

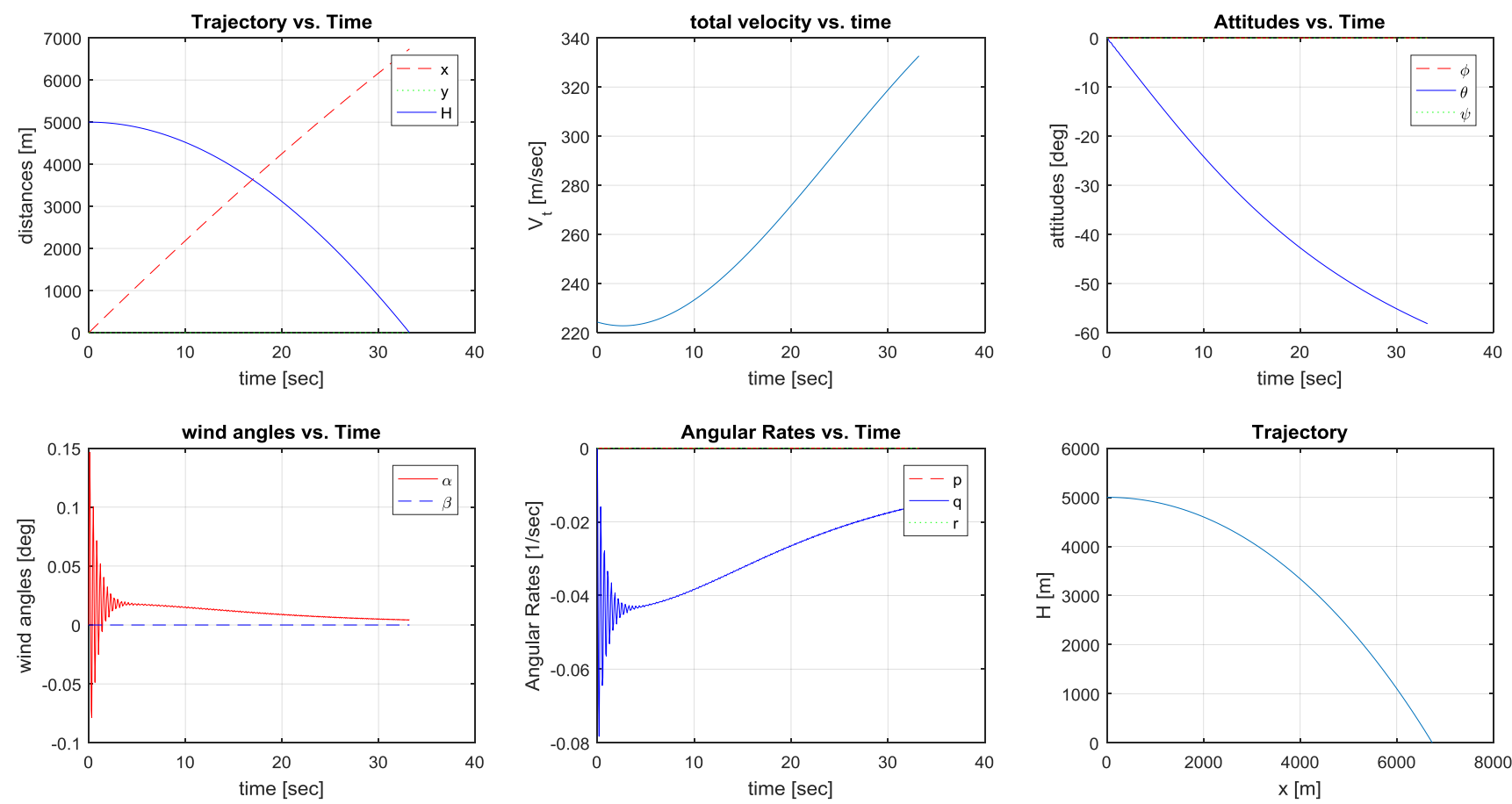

Figure 9 Simulation results of conventional flying body
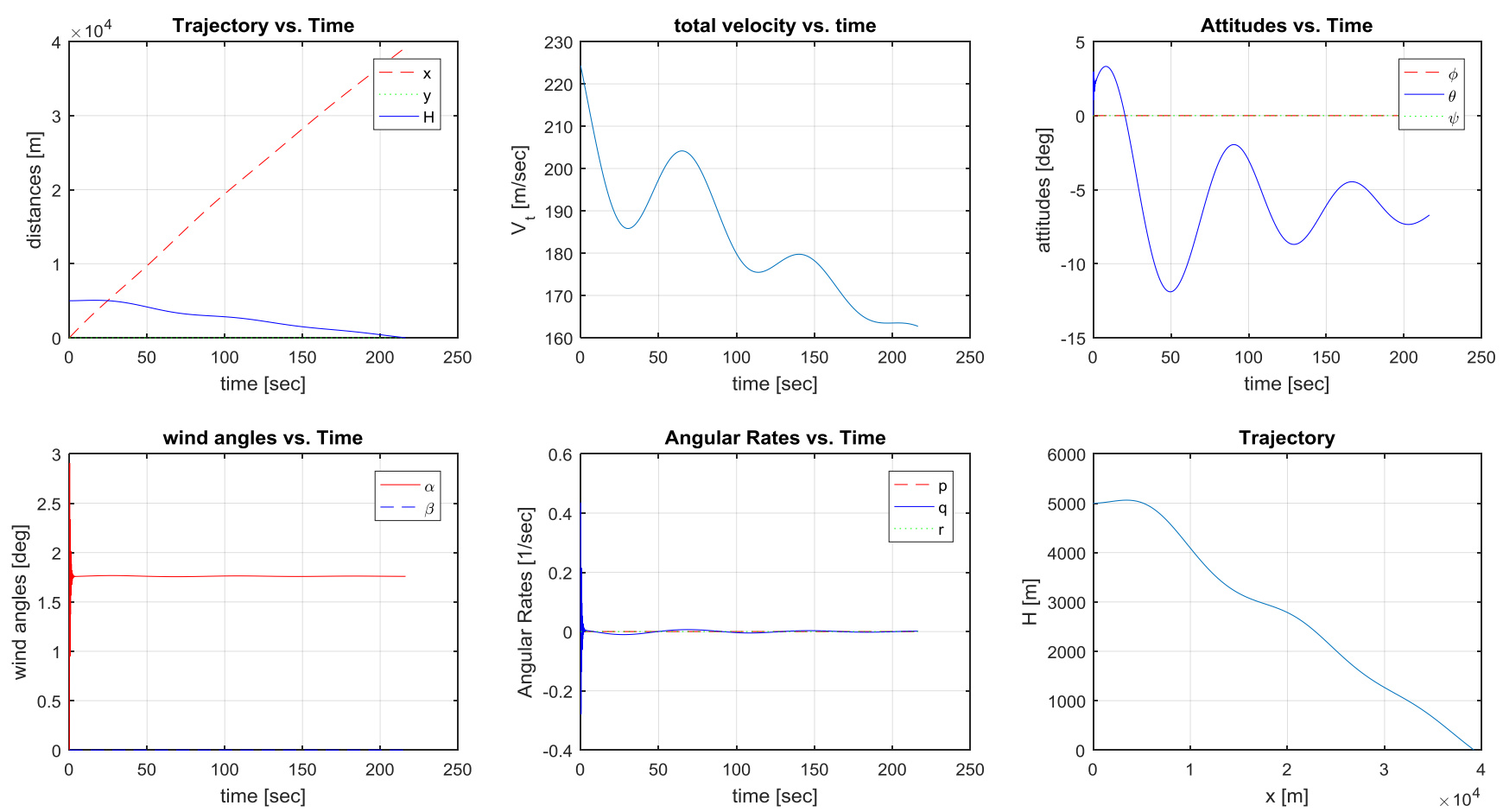

Figure 10 simulation results of $1^{\text {st }}$ method design 

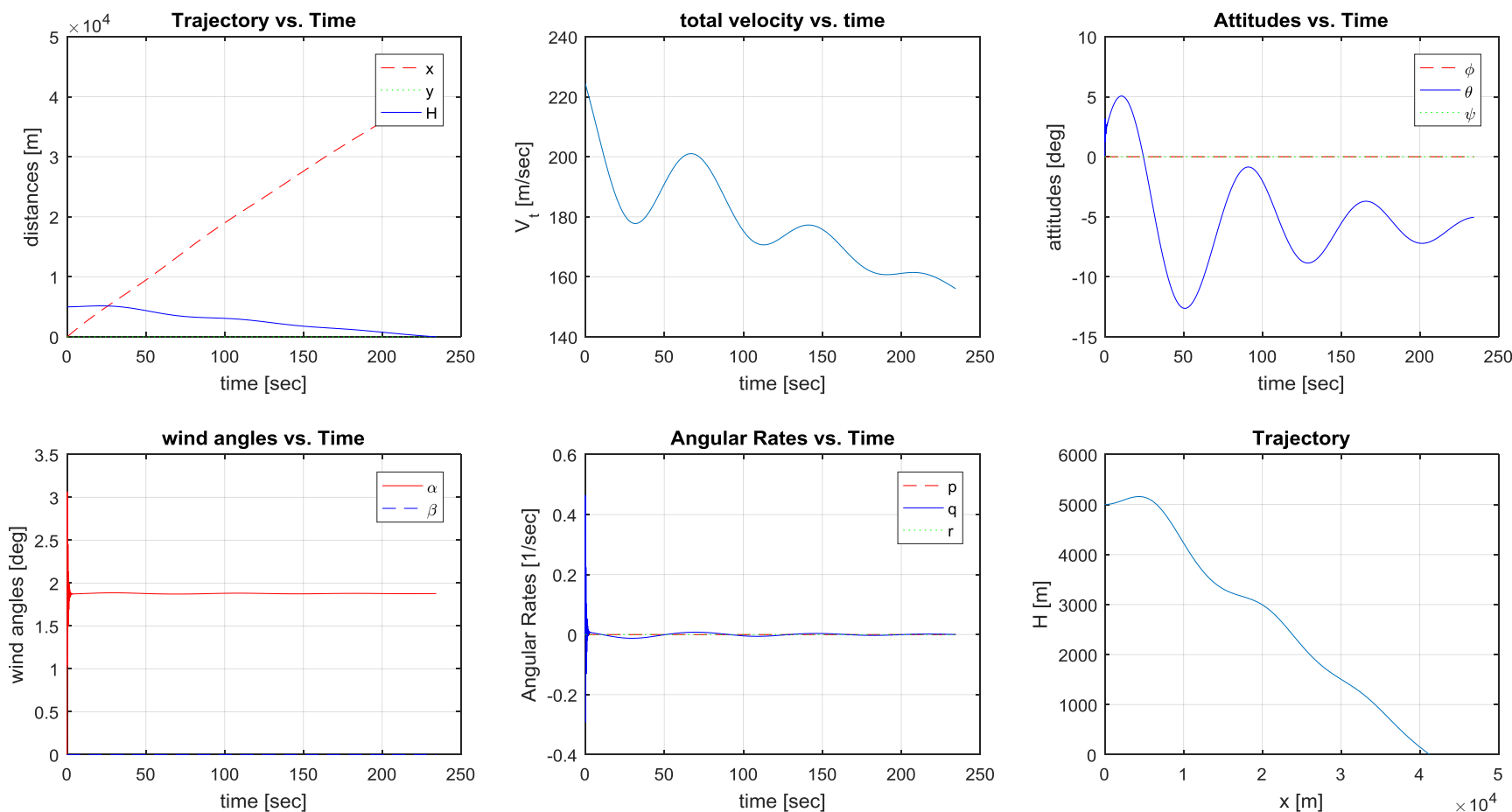

Figure 11. Simulation results of $2^{\text {nd }}$ method design
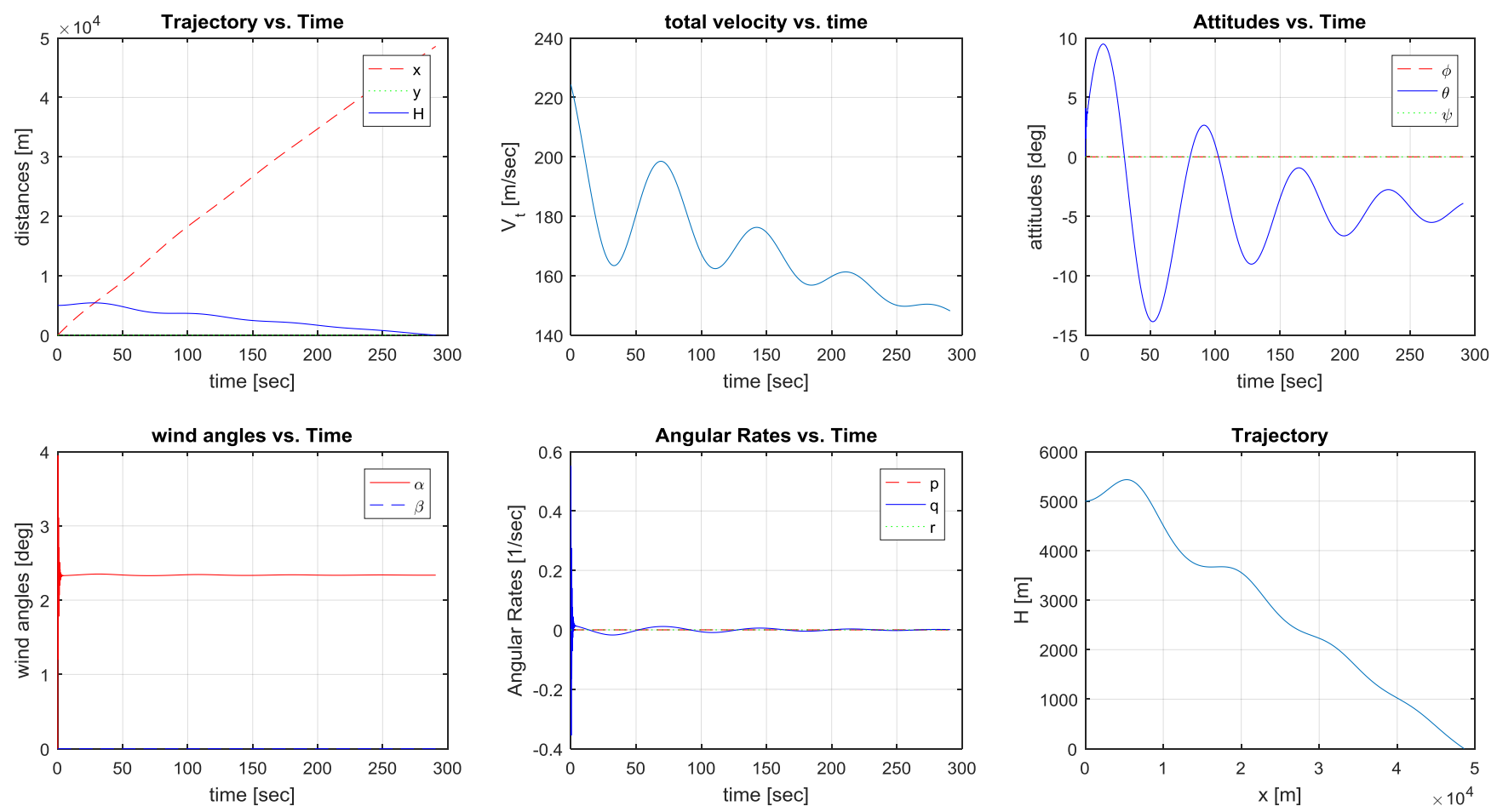

Figure 12. Simulation results of $3^{\text {rd }}$ method design 


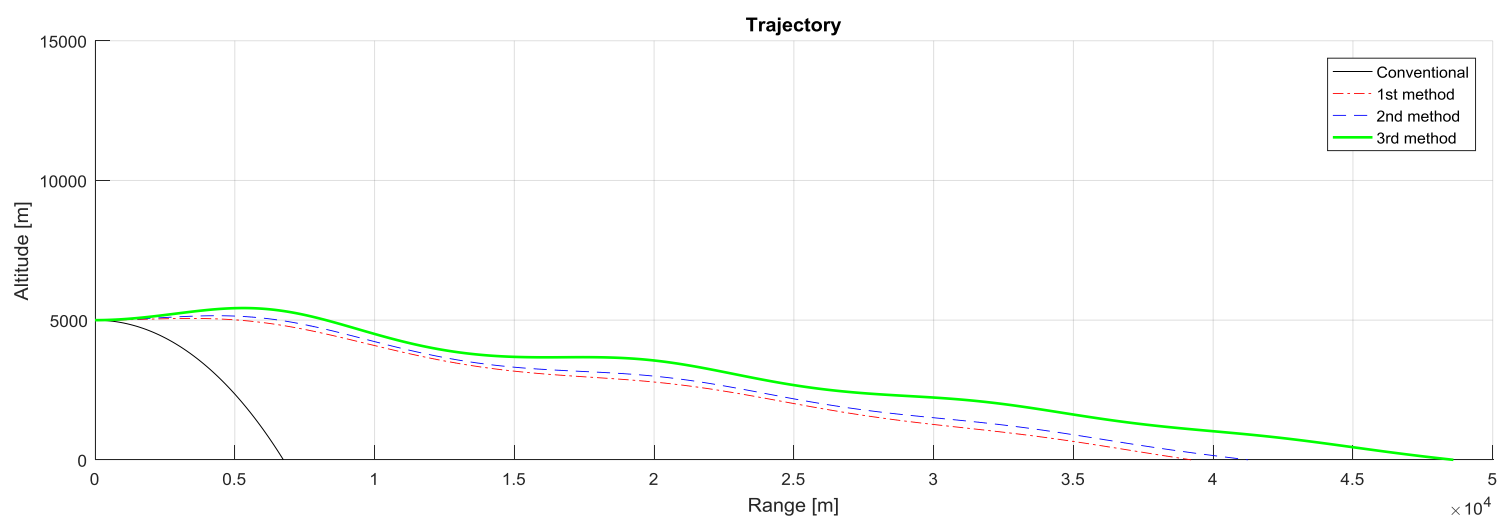

Figure 13. Comparison of Ranges

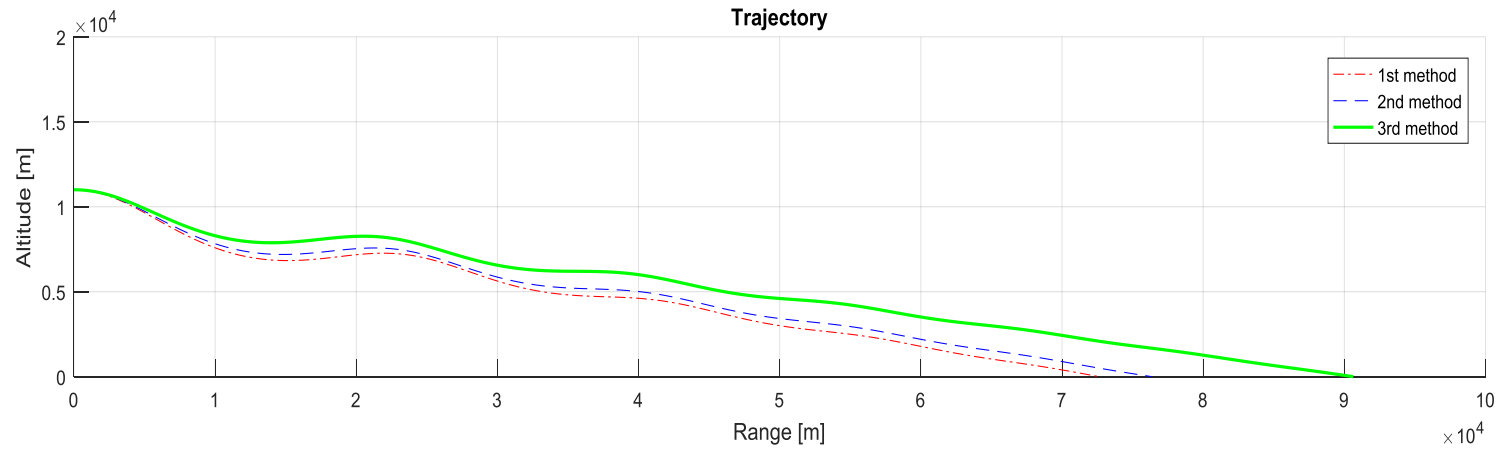

Figure 14. The three designs ranges comparison at $11[\mathrm{Km}]$ release altitude

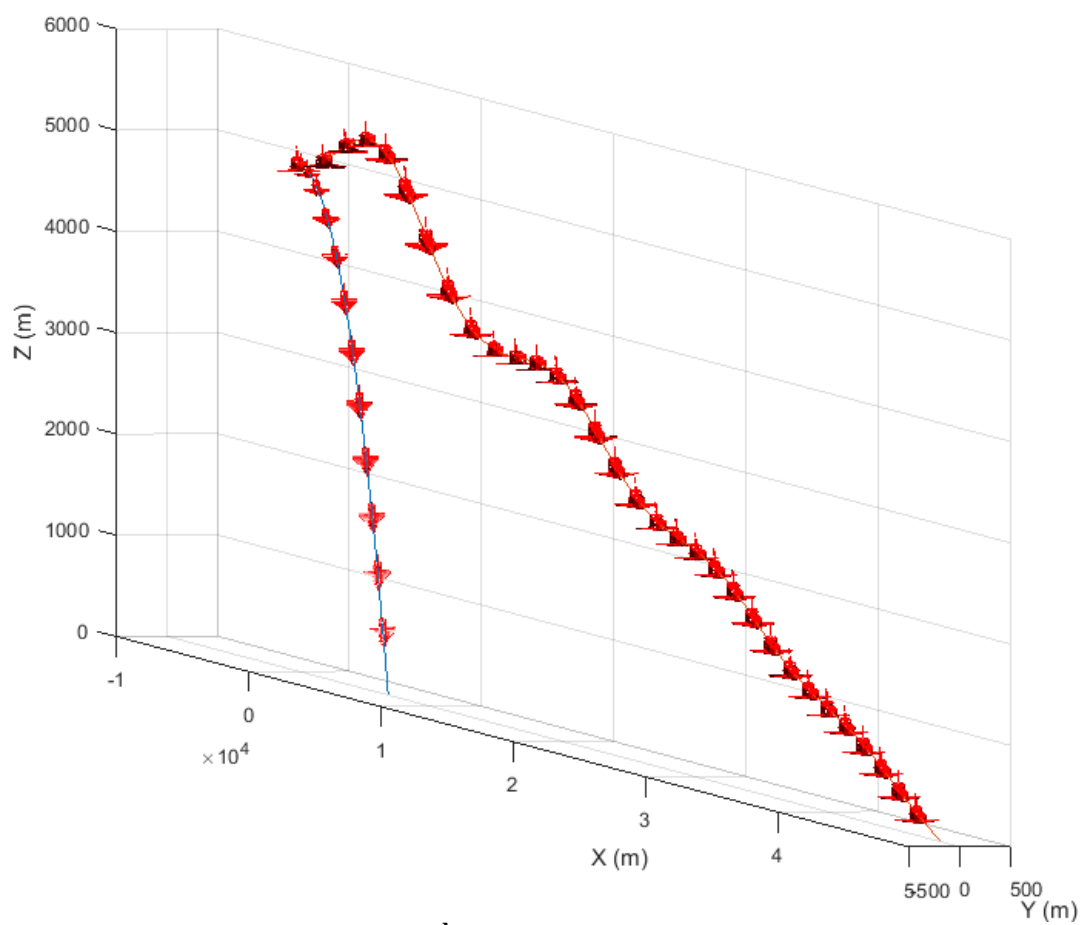

Figure 15. Trajectories of the $3^{\text {rd }}$ method design and conventional flying body

The range of the conventional flying body reaches $6.8 \mathrm{Km}$, the total velocity increases along the trajectory, but the pitch angle and angle of attack are not stable along the trajectory and the flight time is 33 seconds as shown in Figure 9. The three designs are simulated with a fixed pitch deflection angle equals 6 degrees (1.5 for each fin). The range of the $1^{\text {st }}$ method is $39 \mathrm{Km}$ with increment (474\%), so the range is highly increases than the conventional. Also, 
the flying body pitch angle and rate is fluctuating around 6 degrees and $0 \mathrm{sec}^{-1}$ respectively which mean that it is dynamically stable, the angle of attack stabilized at 1.758 degrees, and flight time is 216 seconds as shown in Figure 10. The $2^{\text {nd }}$ method range is $41.24 \mathrm{Km}$ with increment $(506.5 \%)$, pitch angle and pitch rate fluctuate around 6 degrees and $0 \mathrm{sec}^{-1}$ respectively, angle of attack stabilized at 1.88 degrees, and flight time is about 234 seconds as shown in Figure 11. The $3^{\text {rd }}$ method range is $48.6 \mathrm{Km}$ with increment $(614.7 \%)$, pitch angle and pitch rate fluctuate around 4 degrees and $0 \mathrm{sec}^{-1}$ respectively, angle of attack stabilized at 2.335 degrees, and flight time is 291 seconds as shown in Figure 12. This simulations shows that the ranges of the $1^{\text {st }}$ and $2^{\text {nd }}$ are very close to each other whereas they differs only 2.24 $\mathrm{Km}$, the $3^{\text {rd }}$ method pitch angle is less than the $1^{\text {st }}$ and $2^{\text {nd }}$ methods, and the angle of attack stabilized at the highest one which indicates that the $3^{\text {rd }}$ method range should be more than the others. By comparing the ranges, the $3^{\text {rd }}$ method range is higher than the $2^{\text {nd }}$ methods by 7.4 $\mathrm{Km}$ as shown in Figure 13. The $3^{\text {rd }}$ method and conventional flying bodies 3D trajectories are shown with attitudes change in Figure 15.

The maximum release altitude of the conventional flying body is $5 \mathrm{Km}$, but adding the wing and fins allow to increase the release altitude of the flying body. Another simulation is performed for the three designs at $[11 \mathrm{Km}]$ release altitude. The ranges of the flying vehicles is extremely increased where the ranges of the first, second and third designs are 72.6, 76.4, and $90.06 \mathrm{~km}$ with an increment of $(967.65 \%),(1023.53 \%)$, and $(1224.41 \%)$ respectively as shown in Figure 14.

\section{Conclusion}

A completely generic aerodynamic optimization tool with a new geometric parameterization technique for application to nonlinear aerodynamic data has been developed and applied to wing and fins optimization. Linear methods ( $1^{\text {st }}$ and $2^{\text {nd }}$ methods) is used as initial steps for the nonlinear method ( $3^{\text {rd }}$ method) and they give an indication of parametric changing and reduce the $3^{\text {rd }}$ method running time.

The $1^{\text {st }}$ method is effective in choosing the dominant characteristics between stability and maneuverability. If the maneuverability/stability characteristics are the dominant, select a low/high trimming deflection angle respectively. The $2^{\text {nd }}$ method shows more detailed results and has the ability to select a specified characteristic between stability, maneuverability and lift-drag ratio. The $3^{\text {rd }}$ method uses the nonlinear aerodynamic data, and it has many design parameters such as wing and fins sweepback angles. Wing and fins sweepback angles are very effective in drag calculations at high speed. The increase of sweepback angles lead to the increase of the divergence drag Mach number. Consequently, choosing the sweepback angles as design parameters will surly increase the range. The best method is the nonlinear method $\left(3^{\text {rd }}\right.$ method) with range increment is $614.7 \%$ at $5[\mathrm{Km}]$ release altitude. Also the output of the third method can be used as an initial guess for a CFD gradient based optimization method which will magnificently decrease the number of CFD's runs, time and cost.

Adding a range extension kit leads to increase the range with low glide angle. So, if it flies without control, it would hit the target with very low impact angle. The solution of this problem is discussed in details in a next paper under processing where the flying body must trace a designed trajectory. This trajectory has minimum glide angle to get a maximum range, also it has the maximum velocity and impact angle at the collusion. This can be achieved by using inverse dynamics approach to obtain the control deflection angles along the trajectory which allow the flying body to follow the designed trajectory. 


\section{References}

[1] A. Viti, T. Druot, and A. Dumont, "Aero-structural approach coupled with direct operative cost optimization for new aircraft concept in preliminary design," in 17th AIAA/ISSMO Multidisciplinary Analysis and Optimization Conference, 2016, p. 3512.

[2] R. M. Cummings, C. M. Liersch, A. Schütte, and K. C. Huber, "Aerodynamics and conceptual design studies on an unmanned combat aerial vehicle configuration," Journal of Aircraft, pp. 1-21, 2016.

[3] A. M. Kamal, A. Bayoumy, and A. Elshabka, "Modeling and flight simulation of unmanned aerial vehicle enhanced with fine tuning," Aerospace Science and Technology, vol. 51, pp. 106-117, 2016.

[4] S. A. Andrews and R. E. Perez, "Parametric study of box-wing aerodynamics for minimum drag under stability and maneuverability constraints," in 33rd AIAA Applied Aerodynamics Conference, 2015, p. 3291.

[5] A. Kamal, A. M. Aly, and A. Elshabka, "Modeling, analysis and validation of a small airplane flight dynamics," in AIAA Modeling and Simulation Technologies Conference, 2015, p. 1138.

[6] T. Takahashi, "The search for the optimal wing configuration for small subsonic air vehicles," in 12th AIAA/ISSMO Multidisciplinary Analysis and Optimization Conference, 2008, p. 5915.

[7] L. Tang, D. Liu, and P.-C. Chen, "Extension of projectile range using oblique-wing concept," Journal of aircraft, vol. 44, pp. 774-779, 2007.

[8] A. Vicini and D. Quagliarella, "Airfoil and wing design through hybrid optimization strategies," AIAA journal, vol. 37, pp. 634-641, 1999.

[9] S. Austin, "Investigation of range extension with a genetic algorithm," in 7th AIAA/USAF/NASA/ISSMO Symposium on Multidisciplinary Analysis and Optimization, 1998, p. 4880.

[10] M. Anderson and G. Gebert, "Using pareto genetic algorithms for preliminary subsonic wing design," in 6th Symposium on Multidisciplinary Analysis and Optimization, 1996, p. 4023.

[11] S. Wakayama and I. Kroo, "Subsonic wing planform design using multidisciplinary optimization," Journal of Aircraft, vol. 32, pp. 746-753, 1995.

[12] M. Anderson, "The potential of genetic algorithms for subsonic wing design," in Aircraft Engineering, Technology, and Operations Congress, 1995, p. 3925.

[13] B. Etkin, Dynamics of flight: stability and control vol. 3: Wiley New York, 1982.

[14] R. G. . Maydew, "Aerodynamic design of an extended range bomb," Journal of Aircraft, vol. 17, pp. 385-386, 1980. 